Editorial

\title{
Changes in the OPA Editorial Board
}

\section{Relevo en el Comité Editorial de OPA}

Deseo usar el editorial de este número de OPA a modo de despedida de mi labor como Editor de la revista. El pasado 27 de marzo, en la Asamblea anual ordinaria de la Sociedad Española de Óptica, se produjo el relevo natural en la presidencia de nuestra sociedad, iniciando Santiago Vallmitjana su periodo como Presidente. En esa misma Asamblea se produjo mi elección como Vicepresidente de la sociedad.

Las nuevas obligaciones que ese cargo me obligan a asumir hacen aconsejable un relevo en la dirección del Comité Editorial de OPA, para poder mantener la intensidad del trabajo que requiere dicho puesto.

Fue en septiembre de 2005 cuando Felipe Mateos me pasó el testigo y comencé a ocupar el cargo de Editor de OPA, tras tres años en que anteriormente había colaborado ya con Felipe desde el puesto de Secretario de Edición. Ha supuesto un gran honor y una gran responsabilidad que SEDOPTICA haya confiado en mi durante todo este tiempo para desempeñar esta labor. Y quiero agradecer especialmente a los presidentes de SEDOPTICA en este periodo: Santiago Mar, Concepción Domingo, Carlos Ferreira, Joaquín Campos y Santiago Vallmitjana. En todo momento he podido contar con su total confianza y apoyo en todas las iniciativas que hemos abordado.

Durante este periodo de nueve años en que he ocupado el puesto de Editor han sido un total de 421 los artículos publicados, además de frecuentes noticias, y reseñas relacionadas con la Óptica, y con SEDOPTICA, que también han tenido cabida en la revista.

Dejo el cargo de Editor con la sensación del deber realizado. Creo que la revista está en mejor posición que la que encontré. En estos tiempos de "explosión" editorial y de competencia feroz entre revistas y publicaciones científicas, creo que podemos considerar un éxito que
SEDOPTICA haya mantenido la revista OPA, y que ahora publique cuatro números al año con normalidad. Dejo el puesto con la espina de no haber obtenido todavía el índice de impacto, que tan importante sería para la consolidación de OPA. No obstante, la reciente obtención del sello de calidad de la FECYT de OPA, y su catalogación como como revista científica española excelente, creo quo nos permite afrontar el futuro cercano con cierto optimismo.

De todas formas, la posición de OPA es débil, y requiere del compromiso y del interés de todos los que formamos la comunidad científica del ámbito de la Óptica y la Fotónica en nuestro entorno, y de los socios de SEDOPTICA, en particular. Deseo en este último editorial reiterar la invitación a todos a contribuir y potenciar la revista, y muy especialmente a los jóvenes estudiantes que inician una carrera investigadora en nuestro campo, y que pueden encontrar en OPA un excelente vehículo para iniciarse en el mundo de la publicación científica, incluído un premio de iniciación a la investigación.

OPA queda en buenas manos. David Mas ocupará el cargo a partir de este momento. David ha venido actuando como Secretario de Edición durante todo el periodo que he sido Editor, puesto desde el que ha desarrollado una labor esencial para el avance de OPA en estos años.

Por supuesto, dejar el cargo de Editor no va a suponer una desvinculación de OPA, pues desde el nuevo puesto como Vicepresidente de SEDOPTICA seguiré de cerca el día a día de la revista, e intentaré aportar la experiencia adquirida durante este periodo.

Elche, Septiembre de 2014

Ignacio Moreno

Editor de OPA

DOI: http://dx.doi.org/10.7149/OPA.47.3.i 